\title{
RELAÇÕES ENTRE ORÓGENOS, ZONAS DE CISALHAMENTO, QUEBRA CONTINENTAL E DEFORMAÇÕES 3-D. A HISTÓRIA TECTÔNICA DA BACIA SEDIMENTAR DE ALMADA, BAHIA
}

\author{
LUIZ CÉSAR CORRÊA-GOMES ${ }^{1,2}$,JOSÉ MARIA LANDIM DOMINGUEZ ${ }^{2}$, \\ JOHILDO SALOMÃO FIGUEIREDO BARBOSA², IDNEY CAVALCANTIDA SILVA ${ }^{2} \&$ \\ MOISES VIEIRA PINTO ${ }^{2}$
}

\begin{abstract}
OROGENS, SHEAR ZONES, CONTINENTAL BREAK-UP AND 3-D STRAIN RELATIONSHIPS. THE TECTONIC HISTORY OF THE ALMADA SEDIMENTARY BASIN, BAHIA, BRAZIL The Almada Basin is a geometric out-pattern member in the group the onshore coastline sedimentary basins of the Bahia State and neighborhoods. This basin differs from the traditional elongated-shape trending Camamú and Reconcavo-Tucano-Jatobá basins, and shows a compact rhombohedral arrangement following $\mathrm{N} 45^{\circ}, \mathrm{N} 90^{\circ}, \mathrm{N} 120^{\prime \prime} \mathrm{e} \mathrm{N}-\mathrm{S}$ structural lineaments. This shape directly or indirectly reflects a specific geological history influenced by the paleoproterozoic and neoproterozoic orogens, neoproterozoic shear zones and mesozoic supercontinent break-up. Several sets of fault and fractures were kinematically studied inside and around the basin, and the main stress tensors obtained using inversion methods. The structural study of the Almada Basin allowed to recognize that: (i) the initial tectonic activity was controlled by normal faults, with orthorhombic-romboedral 3-D extensional strain pattern, followed by transtensional ones characterizing the Almada Basin as a polyphasic tectonic basin, and (ii) during the transtensive phase this basin was affected by at least two almost orthogonal extensional events, indicating a possible $\sigma_{1}$ orientation inversion during its formation and tectonic evolution. These data are crucial for prospecting groundwater and hydrocarbon in the basin onshore and offshore areas.
\end{abstract}

Keywords: Almada Basin, orogens, shear zones, continental break-up, 3-D strain.

Resumo A Bacia de Almada é um elemento fora do padrão geométrico das bacias sedimentares litorâneas onshore do estado da Bahia e vizinhanças. Ela foge total on parcialmente do formato alongado e alinhado aproximadamente N-S das bacias de Camamú e Recôncavo-Tucano devido ao seu formato romboédrico compacto praticamente todo esculpido sobre lineamentos $\mathrm{N}^{\circ} 5^{\circ}$, N90, $\mathrm{N} 120^{\circ}$ e N-S. Cada lineamento conta uma história de formação que reflete direta ou indiretamente a influência de orógenos paleoproterozóico e neoproterozóico, de zonas de cisalhamento neoproterozóicas e de rupturas de supercontinente no Mesozóico. Nessa bacia e em suas cercanias foram estudados cinematicamente vários conjuntos de falhas e fraturas e obtidos por métodos de inversão os campos de tensão geradores das mesmas que revelaram padrões indicativos de que: (i) inicialmente a bacia foi dominada por falhas normais, com padrão deformacional ortorrombico-romboédrico triaxial, que evoluíram para falhas transextensionais, o que caracteriza a Bacia de Almada como polifásica, e (ii) na fase transextensional a bacia passou por, pelo menos, dois eventos extensionais importantes (ou sub-eventos), quase ortogonais entre si, o que indica uma possível inversão de orientação dos tensores máximos principais durante sua formação e sua evolução tectônica. Eșsas informações são cruciais para prospeç̧ão de água subterrânea e hidrocarbonetos nas regiões continentais e offshore da Bacia de Almada.

Palavras-chave: Bacia de Almada, orógenos, zonas de cisalhamento, quebra continental, deformação 3-D.

INTRODUÇÃo A Bacia de Almada é um elemento geométrico discrepante dentre as bacias sedimentares litorâneas do estado da Bahia. Possui formato romboédrico e aflora no continente em pequena área aproximadamente a norte-nordeste da cidade de Ilhéus. Assim como a Bacia de Camamú, tem despertado o interesse de companhias de prospecção por apresentar boa potencialidade para extração de hidrocarbonetos em ambiente plataformal, aumentando a importância do entendimento da sua construção estrutural em ambiente continental para, depois, poder estender esse conhecimento para as porções offshore da bacia. Entender como essa bacia foi formada, o controle exercido pelas estruturas herdadas do embasamento, os padrões de falhamento produzidos, as principais orientações tensionais e qual o significado dos campos de tensão geneticamente associados à formação e à evolução da Bacia do Almada são os objetivos desse trabalho.
GEOLOGIAREGIONAL ABacia mesozóica de Almada (Fig. 1) situa-se a norte da cidade de Ilhéus no estado da Bahia, estando alojada parte nos granulitos da porção sul do Cinturão paleoproterozóico Itabuna-Salvador-Curaçá (Barbosa \& CorrêaGomes 2003), de foliação principal local em torno de N00 $-10^{\circ}$, e parte no Sienito neoproterozóico de Itabuna. Mais a sul, próximo à fronteira com o estado de Minas Gerais, aparecem as unidades metassedimentares meso-neoproterozóicas do Grupo Rio Pardo, sienitos neoproterozóicos da Suíte Alcalina do Sul da Bahia, além do Orógeno neoproterozóico Araçuaí (Pedrosa-Soares et al. 1992,2001) que teve fundamental importância na formação do par conjugado das Zona de Cisalhamento de Potiraguá - ZCP, orientada N140", e de Itabuna-Itajú do Colônia - ZCIIC, orientada N45", em cuja extremidade NE se instalou a Bacia de Almada. A ZCIIC apresenta complexa geometria (Corrêa-Gomes 2000) que começa

1 - Departamento de Ciências Aplicadas, Centro Federal de Educação Tecnológica da Bahia, Rua Caetano Moura s/n, Barbalho, CEP: 40030-150, Salvador, Bahia, Brasil/ Departamento de Geologia, Instituto de Geociências -UFBA, Rua Barão de Geremoabo, 123, Campus de Ondina, Salvador. Bahia, Brasil. E-mails: gomes@cefetba.br, Iccgomes@ufba.br.

2 - Departamento de Geologia, Instituto de Geociências -UFBA, Rua Barão de Geremoabo, 123, Campus de Ondina, Salvador, Bahia, Brasil. E-mail: josc_landim@uol.com.br, johildo@cpgg.ufba.br, idney25@ig.com.br, geofisica.ufba@gmail.com 
com flancos assimétricos de mergulhos para NW e evolui para uma estrutura em flor conforme se afasta do orógeno Araçuaí e adentra o Cráton do São Francisco. Essa configuração foi retomada pela Bacia de Almada durante a separação continental mesozóica.

\section{OORÓGENO ITABUNA-SALVADOR-CURAÇÁ NAÁREA}

ESTUDADA O Orógeno Itabuna-Salvador-Curaçá é representado, na área estudada, pelo Cinturão paleoproterozóico Itabuna
(Barbosa \& Dominguez 1996, Barbosa \& Sabaté 2004) constituído por granulitos máficos a intermediários com estruturas planares próximas de N-S e mergulhos subverticais. Nessa área, pelo menos, três fases deformacionais podem ser definidas (Fig.2): (i) a mais antiga $\left(\mathrm{F}_{n+1}\right)$ que deformou uma foliação pré-existente $\left(\mathrm{S}_{n}\right)$, com formação de dobras isoclinais recumbentes de planos axiais $(\mathrm{S})$ e eixos sub-horizontais, estes últimos caracterizados por lineações de estiramento-crescimento mineral do tipo dip-slip e marcadores cinemáticos (e.g. foliações $\mathrm{S}-\mathrm{C}$ e assimetria de cristais

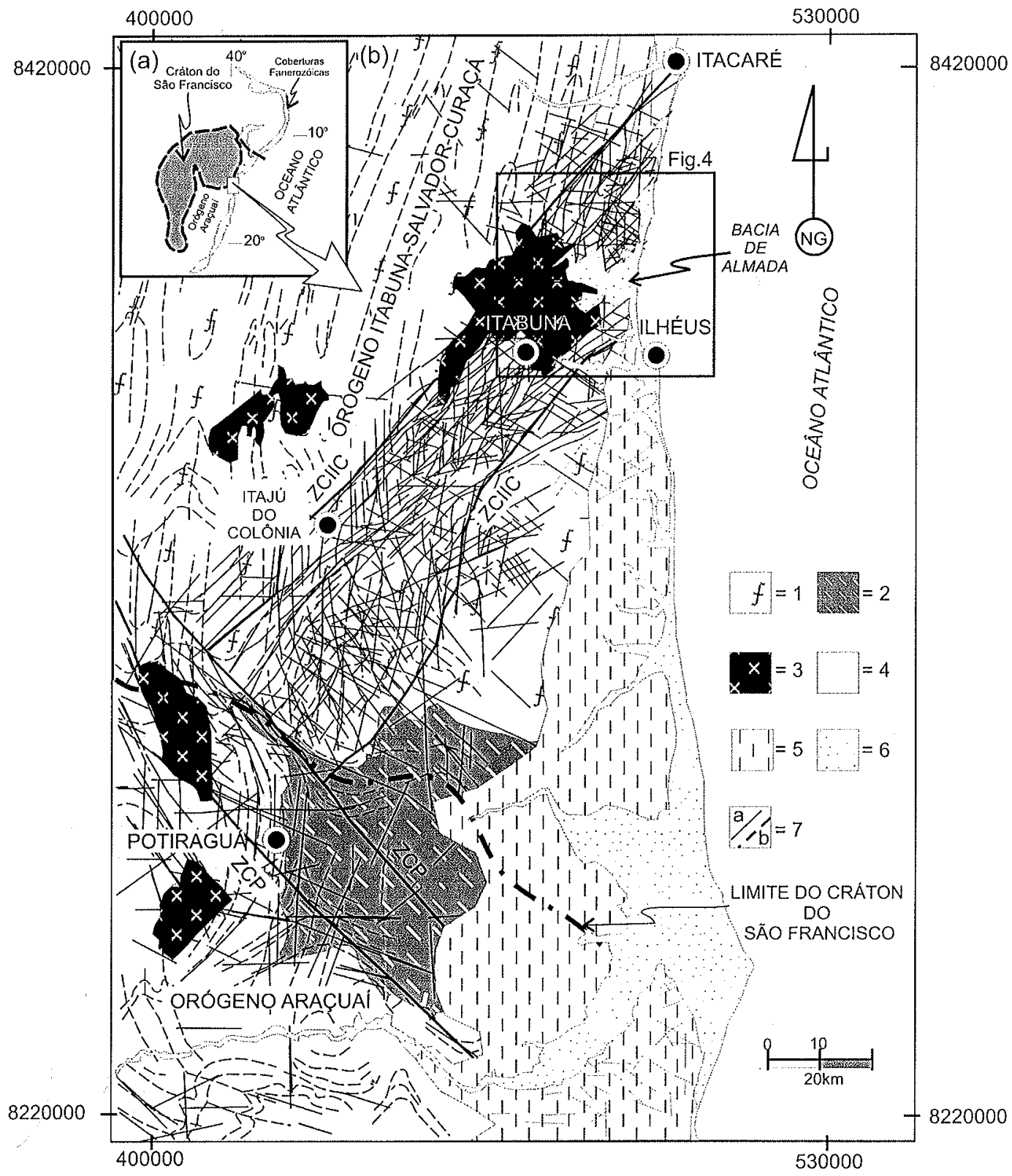

Figura l - (a) Delimitação da área em relação ao Cráton do São Francisco e Orógeno Araçuaí (inset superior esquerdo) e (b) localização da Bacia de Almada no contexto dos Orógenos paleoproterozóico Itabuna-Salvador-Curaçá e neoproterozóico Araçuaí e das Zonas de cisalhamento Itabuna-Itajú do Colônia - ZCIIC e Potiraguá - ZCP. Os feixes de lineamentos no mapa foram obtidos pela interpretação de foto-aéreas, imagens de radar e satélite e mapa de modelagem de relevo. $1=$ Orógeno Itabuna-SalvadorCuraçá, representado na área estudada pelo Cinturão Itabuna; $2=$ Grupo Rio Pardo; $3=$ Sienitos da Província Alcalina do Sul da Bahia; 4= Orógeno Araçuaí; 5= Grupo terciário Barreiras; $6=$ Coberturas terciário-quaternárias e Bacia de Almada e $7=$ Lineamentos: $a=$ rúpteis e $b=$ dúcteis. $O$ retângulo demarca a área da Figura 4. 


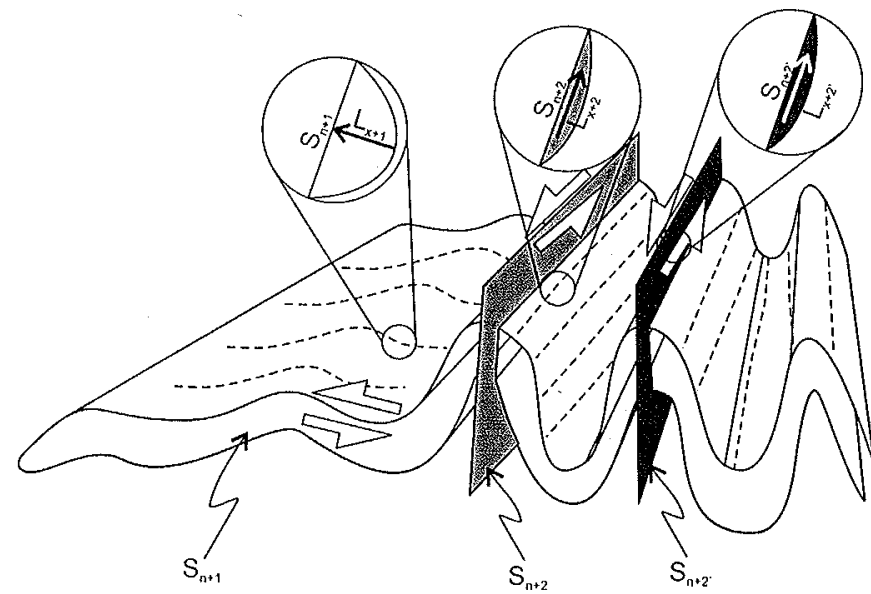

Figura 2 - Esquema tridimensional das estruturas impressas pelas fases tectônicas que afetaram o Orógeno Itabuna-SalvadorCuraçá na área estudada, com indicação da orientação das superficies e lineações minerais, em rede estereográfica igualárea, Schmidt-Lambert, no hemisfério inferior. As setas nos grandes círculos indicam a movimentação do bloco ausente (missing block) de cada fase, ou sub-fase, tectônica.

$\sigma$ e $\delta$ ) indicando movimentação reversa de $E$ para $W$; (ii) a fase $\left(\mathrm{F}_{n+2}\right)$ interpretada como de evolução progressiva ao evento $\left(\mathrm{F}_{n+1}\right)$ gerou, em zonas de high strain, dobras apertadas de orientação geral $\mathrm{N} 00^{\circ}$ a $\mathrm{N} 10^{\circ}$, com planos axiais subverticias $\left(\mathrm{S}_{n+2}\right)$. e eixos/ lineações de baixo caimento. Estas lineações são do tipo strikeslip, embora localmente possam ser notadas torções que as inclinam. A essa segunda fase se relaciona a uma transpressão de cinemática sinistral que, ao dobrar a superfície anterior $\left(\mathrm{S}_{n+1}\right)$, de modo fechado a isoclinal, forma faixas com cinemática alternada reversa-normal. Nas etapas tardias da segunda fase, outra subfase $\left(\mathrm{F}_{n+2}\right)$ também pode ser notada, apesar de apresentar grau de penetratividade mais fraco que as anteriores. Esta é marcada pela presença de zonas de cisalhamento transcorrentes sinistrais, subverticais, subparalelas aos planos axiais da $S_{n+2}$, constituindo também lineações tipo strike-slip, podendo localmente evoluir até a transposição das estruturas anteriores. Assim, a deformação transamazônica resultou na área estudada, uma forte foliação, não raramente milonítica, $\mathrm{N} 00^{\circ}$ a $\mathrm{N} 10^{\circ}$ com mergulhos subverticais principalmente para $\mathrm{E}, \mathrm{e}$, subordinadamente, para $\mathrm{W}$.

\section{ZONAS DE CISALHAMENTO DE ITABUNA-ITAJÚ DOCO.} LÔNIA E DE POTIRAGUÁ Orientada $N 45^{\circ}$ e apresentando dimensões de $150 \mathrm{~km}$ por $30 \mathrm{~km}$, a Zona de Cisalhamento de Itabuna-Itajú do Colônia - ZCIIC, é um dos mais importantes grupos de lineamentos do SSE do estado da Bahia. Tem íntima relação com a Província Alcalina do Sul do estado da Bahia - PASEBA (Silva Filho et al. 1974 , Conceição \& Otero 1996), representada pelo Sienito de Itabuna na área estudada. Foi descrita por Silva Filho et al. (1974), Mascarenhas (1979) e Lima et al. (1981) que sublinharam as relações genéticas entre a ZCIIC e PASEBA. A ZCIIC foi posteriormente detalhada por Arcanjo (1993) e Martins \& Santos (1993) que destacaram a cinemática dextral como o último movimento importante registrado, e por Corrêa-Gomes et al. (1998) que observaram uma cinemática sinistral anterior à dextral, caracterizando-a como uma zona de cisalhamento transcorrente polifásica. A ZCIIC forma um par conjugado com a Zona de Cisa- lhamento de Potiraguá - ZCP, orientada N140", e ambas estão ligadas à colisão do Orógeno Araçuaí com o Cráton do São Francisco no Neoproterozóico (Pedrosa-Soares et al. 1992,2001). Em vista disto, para o seu melhor entendimento geométrico e tectônico, essas zonas de cisalhamento serão descritas conjuntamente. Enquanto a ZCP se alojou nas proximidades do limite tectônico entre o orógeno e o cráton, a ZCIIC parte desta interface e adentra o cráton de modo praticamente ortogonal a este limite. Quanto aos campos de paleotensão, o estudo cinemático de fraturas e falhas da ZCIIC e da ZCP revelou a existência de dois eventos tectônicos distintos (Corrêa-Gomes \& Oliveira 2002, Corrêa-Gomes et al. 2005): (i) um compressional, entre 620Ma e $570 \mathrm{Ma}$, associado à colisão do Orógeno Araçuaí com o cráton com duas orientações, uma mais antiga $\mathrm{N}-\mathrm{S}$ e outra mais nova $\mathrm{E}-\mathrm{W}$ e (ii) um extensional entre $550 \mathrm{Ma}$ e $470 \mathrm{Ma}$, relacionado ao relaxamento do orógeno com orientações N-S antecedendo orientações E-W.

Um esboço da configuração tridimensional dessas zonas de cisalhamento, obtido por estudo da disposição espacial das principias estruturas rúpteis foi realizado por Corrêa-Gomes (2000) e Corrêa-Gomes et cl. (2000) pela coleta de 6307 planos de falhas e fraturas com orientação próximas a $N 45^{\circ} \mathrm{e} N 140^{\circ} \mathrm{em}$ vários blocos dessas ZCs (Fig.3). Desse total, 1153 pertencem a ZCP, correspondendo ao bloco $\mathrm{P}$, e 5154 a ZCIIC, sendo que 1426 referem-se ao bloco IIC-1, 1802 ao bloco IIC-2 e 1926 ao bloco IIC-3.

Na ZCP pode ser notado que a maioria dos planos de falhas e fraturas N $140^{\circ}$ mergulha forte para SW, porém alguns têm mergulho suave também para SW. Ademais há razoável quantidade de

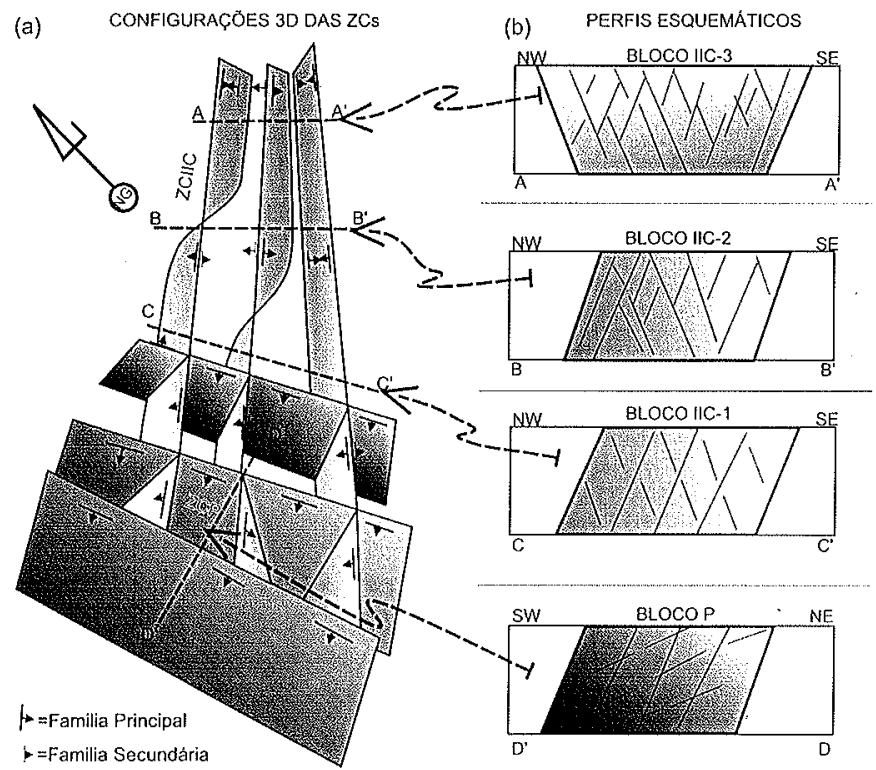

Figura 3 - Esquemas: (a) da estrutura 3-D das zonas de cisalhamento de Itabuna-Itajú do Colonia, ZCIIC, e Potiraguá, ZCP, com base na interpretação de 6307 planos de falhas e fraturas com orientações próximas a $\mathrm{N4}^{\circ}$ e N140'; as inclinações dos flancos estão exageradas para uma melhor visualização (CorrêaGomes 2000) e (b) dos perfis dos blocos estudados com indicação dos principais planos rúpteis (linhas continuas) e secundários (linhas tracejadas). Notar a progressiva torção dos flancos esquerdo e central da ZCIIC conforme se afasta, de SW para NE, da interface orógeno/cráton. 
planos $N 45^{\circ} \mathrm{com}$ forte mergulho para NW, principalmente, e para SE. Na ZCP, o conjunto de planos de falhas e fraturas de direção $\mathrm{N} 140^{\circ}$, de forte mergulho para $\mathrm{SW}$, predomina sobre o de mergulhos mais suaves. A numerosa presença de planos de falhas e fraturas $\mathrm{N} 45^{\circ}$, neste domínio, atesta que houve forte interferência da ZCIIC sobre a ZCP.

Com base nestes dados, a estruturação planar rúptil predominante da ZCP é assimétrica, orientada $\mathrm{N} 140^{\circ}$ e com tendência a acentuado mergulho para SW.

Na ZCIIC, no sentido faixa móvel-cráton, ocorrem, de SW para $\mathrm{NE}$, os seguintes arranjos geométricos das famílias de falhas e fraturas, todas com mergulho sub-vertical a vertical. No bloco IIC1, é notável a presença de planos $\mathrm{N} 140^{\circ}$, a maioria mergulhando para SW, e de planos $N 45^{\circ}$ apresentando tendência de mergulhos para NW. No bloco IIC-2, nas suas bordas, a maioria dos planos $\mathrm{N} 45^{\circ}$ mergulha para $\mathrm{NW}$, enquanto no centro os mesmos tendem a mergulhar para SE. No bloco IIC-3 nas bordas os planos apresentam mergulhos convergentes para o interior, enquanto no centro a tendência é a de mergulharem para SE.

Assim, da faixa móvel para o cráton, a porção sudoeste a ZCIIC tem uma forte influência de planos N140 ${ }^{\circ}$ da ZCP e geometria assimétrica com mergulhos principalmente para NW. Na porção central a ZCIIC as bordas têm mergulhos para NW e, no centro, mergulhos para SE. Na porção nordeste as borda da ZCIIC têm estrutura simétrica com mergulhos centro-convergentes, do tipo palm-tree, enquanto que no centro os planos mergulham para SE. Como será exposto mais adiante, esta geometria é idêntica a da Bacia de Almada.

ABACIADEALMADA A Bacia de Almada recebeu esse nome por se situar na desembocadura do Rio Almada, a norte da cidade de Ilhéus. Possui geometria na sua porção onshore totalmente diferente das demais bacias litorâneas mesozóicas do estado da Bahia. Sua forma é romboédrica curta e compacta, fortemente controlada por lineamentos estruturais $\mathrm{N}^{\circ} 5^{\circ}, \mathrm{N}-\mathrm{S}, \mathrm{N} 120^{\circ}$ e N $90^{\circ}$. Seu embasamento consiste de granulitos paleoproterozóicos do Cinturão Itabuna e a SSW o sienito de Itabuna (Fig.4). Na região offshore ocorre o Canyon do Almada de eixo maior N120 $-130^{\circ}$. A Bacia de Almada foi estudada na região continental por Carvalho (1965), Bruhn \& Moraes (1989)e, mais recentemente, por D'Ávila et al. $(2002,2004)$ e Karam (2005). Seu contexto estratigráfico compreende as Formações Urucutuca (sedimentos turbidíticos de talude) e Aliança e Sergi, (sedimentos flúvio-eólicos).

A importância do estudo da cinemática e da dinâmica das fálhas e fraturas dos afloramentos continentais da bacia deve-se a que: (i) essa análise é difícil de ser feita em regiões offshore, (ii) o estudo no continente possibilita inferir, por analogia, respostas mecânicas semelhantes para offshore, e (iii) pode resultar em subsídios para a prospecção de hidrocarbonetos onshore e offshore, e também de água subterrânea onshore.

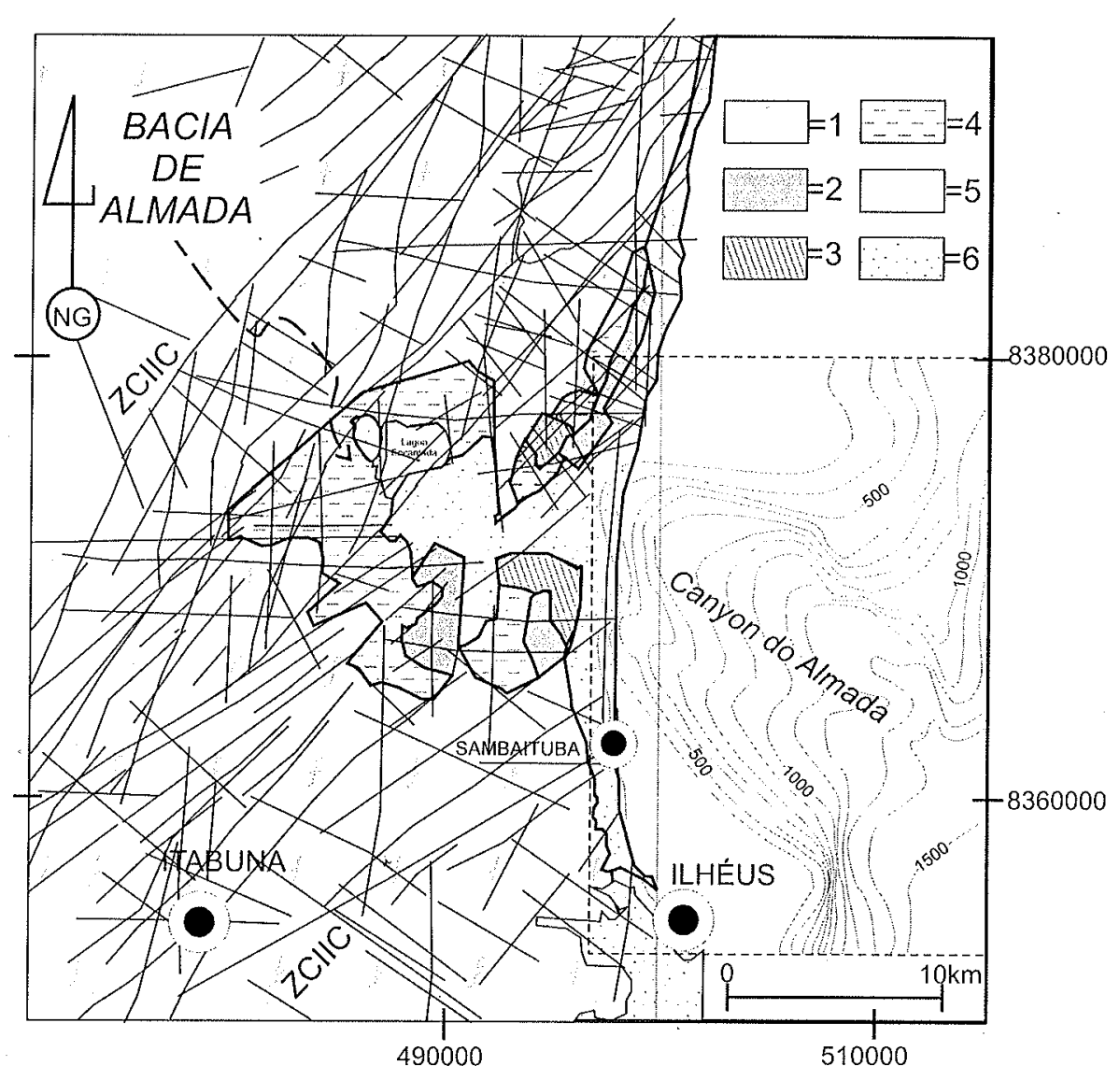

Figura 4 - Mapa geológico simplificado da Bacia de Almada, com indicação dos principais lineamentos rúpteis e delineação do Canyon do Almada tendo como base as isópacas da região offshore da bacia. $1=$ Embasamento cristalino (Cinturäo Itabuna + Sienito de Itabuna); $2=$ Grupo Almada/Camamí; 3 = Grupo Urucutuca; $4=$ Grupo Sergi/Aliança; $5=$ Grupo Barreiras e 6= Depósitos marinhos e continentais costeiros (modificado de Barbosa \& Dominguez 1996 e Brunh \& Moraes 1989). 
MÉTODOS A sistemática de trabalho consistiu da coleta de dados planares e lineares (estrias de deslizamento e degraus) e dedução das cinemáticas associadas a esses planos por meio do estudo de marcadores cinemáticos de falhas e fraturas do interior da Bacia de Almada e do embasamento circunvizinho. Com os mesmos objetivos e para efeitos de comparação foi realizada uma secção ortogonal à Zona de Cisalhamento de Itabuna-Itajú do Colônia, nas proximidades e a SE da Bacia de Almada. A análise desses dados possibilitou deduzir as orientações 3D dos campos de tensão por meio do método de inversão com uso do programa Faultkin ${ }^{\circledast}$ (Allmendinger 2001). Os dados planares da deformação rúptil e os tensores principais de cada afloramento foram transferidos para bancos de dados e plotados em redes estereográficas igual-área (Schmidt-Lambert), como pólos e linhas, e obtidas curvas de isofrequiência e rosáceas de direção (de $10^{\circ}$ em $10^{\circ}$ ) para melhor visualizar as orientações mais marcantes. Por uma questão logística e melhor filtragem do significado dos diferentes campos de tensão obtidos, optou-se por tratar em separado das informações obtidas: (i) no embasamento afetado pela ZCIIC na secção a SW bacia aqui chamado de embasamento distal, e (ii) no embasamento afetado pelas falhas limítrofes da bacia, chamado aqui de embasamento proximal, e nas suas formações sedimentares. No último caso, separou-se ainda as falhas normais das transcorrentes. Quando o $\sigma$ revelou ser mais vertical, como no caso das falhas normais, utilizou-se o gráfico adicional de rosáceas de orientação direcionais de $\sigma_{3}$, para melhor visualizar as direções de extensão na bacia.

ESTRUTURAS RÚPTEIS Ao todo foram medidos e estudados cinematicamente 7194 planos de falhas e fraturas na área, sendo 6465 no embasamento, na seç̧ão a SW da bacia, e 729 nas falhas limítrofes e formações sedimentares (Fig.5). Em ambos os casos a maioria dos planos medidos possuiu mergulhos fortes e suas vergências merecerão detalhamento adiante.

\section{(a) Falhas e Fraturas - Embasamento distal (6465 medidas)}
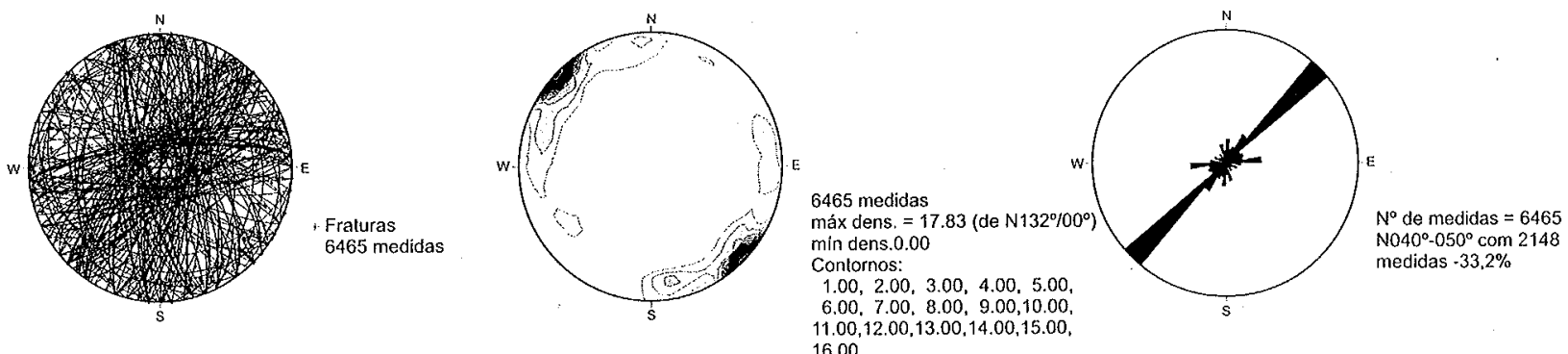

(b) Falhas e Fraturas - Embasamento distal sem orientações N040 $-050^{\circ}$ (3789 medidas)
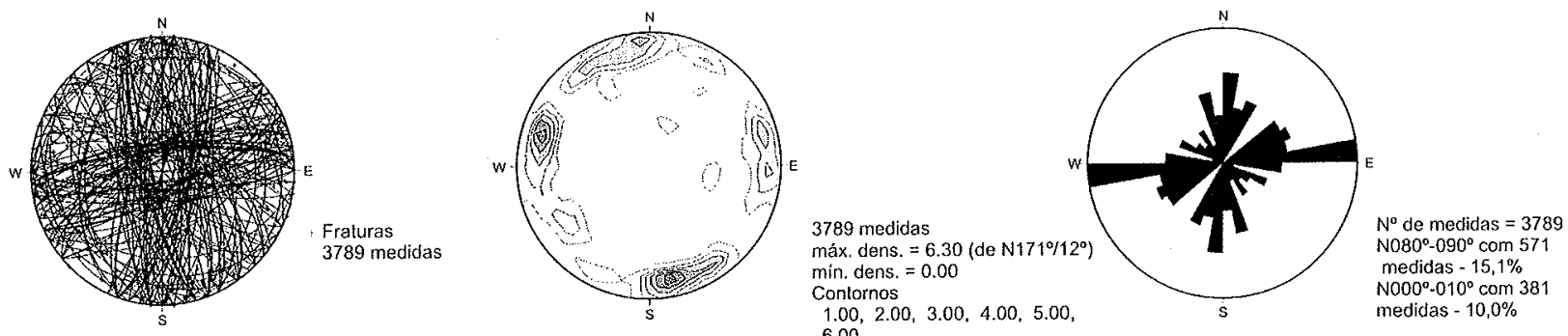

(c) Falhas e Fraturas - Bacia de Almada (729 medidas)
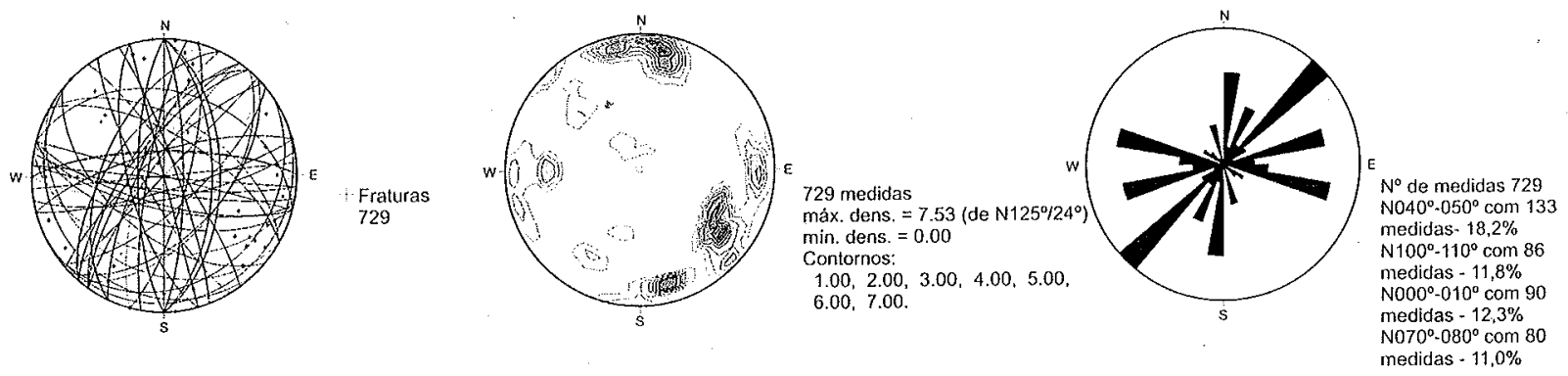

Figura 5 - Plotagem dos planos de falhas e fraturas - como grandes círculos e em campos de isodensidade em rede estereográfica igual-área, hemisfério inferior, e em rosáceas de direçôes, intervalos de $10^{\prime \prime}$ - dos embasamentos distal, incluído (a) e excluído (b) lineamentos $N 40^{\prime \prime}-50^{\prime}$, e proximal e pacotes sedimentares da Bacia de Almada (c). 
Estruturas rúpteis do embasamento distal da Bacia deAlmada $\mathrm{A}$ figura 5a mostra que as estruturas planares têm padrão simétrico de convergência de falhas para o centro da ZCIIC, com máximo de concentração $(17,83 \%) \mathrm{em} \mathrm{N} 132 \% 00^{\circ}$ e no quadrante NW concentração diametralmente oposta. Essa distribuição é melhor observada na rosácea de direção na qual planos se concentram entre $\mathrm{N} 40^{\circ}-50^{\circ}(33,2 \%)$, e entre $30^{\circ}-40^{\circ}(8,2 \%)$. A quantidade de falhas e fraturas orientadas próximas a $\mathrm{N} 40^{\circ}-50^{\circ}$ é tamanha que foi necessária outra rosácea de direção com a retirada desse set direcional, para permitir destacar outros conjuntos importantes (Fig.5b). A retirada dos planos de orientação próxima a da ZCIIC resultou em 4317 planos com máximo polar de $\mathrm{N} 171^{\circ} / 12^{\circ}(5,7 \%)$ e possibilitou a melhor observação dos planos entre N80 $-90^{\circ}(15,1 \%), \mathrm{N} 30^{\circ}-40^{\circ}$ $(11,5 \%)$ e $\mathrm{N} 00^{\circ}-10^{\circ}(10,0 \%)$. Esse comportamento espacial dos planos de falhas e fraturas da ZCIIC está em sintonia com o anteriormente descrito sobre a sua evolução geométrica 3-D no sentido do limite entre o orógeno Araçuaí/Cráton do São Francisco e posições mais intracratônicas.

Estruturas rúpteis associadas à Bacia de Almada Ao todo 729 medidas planares foram plotadas (Fig.5c) com máximo polar em $\mathrm{N} 132 \% 0^{\circ}(7,5 \%)$ e na rosácea de direção correspondente, se destacam as direções $\mathrm{N} 40^{\circ}-50^{\circ}(18,2 \%)$, próximas a E-W, N100 $-110^{\circ}$ $(11,8 \%)$ e N70 $-80^{\circ}(11,0 \%)$, e NOO $-10^{\circ}(12,3 \%)$.

CAMPOS DE TENSÃO Do estudo cinemático de fraturas e falhas obteve-se um total de 215 orientações de campos de tensão, 182 delas na secção a SW, correspondente ao embasamento distal da bacia, e 33 nas falhas que controlam a bacia e nas coberturas sedimentares que a preenchem.

Campos de tensão no embasamento distal da Bacia de Almada Tendo em vista que mais de $80 \%$ dos tensores máximos principais da Zona de Cisalhamento de Itabuna-Itajú do Colônia apresentaram caimento inferior à $30^{\circ}$ e que a maioria estive relacionada a movimentos transcorrentes, foi possível representá-los em rosáceas de direção. Essa plotagem (Fig.6a) mostra, a partir de 182 medidas, a predominância de duas orientações de $\sigma$ coincidentes com aquelas obtidas por Corrêa-Gomes (2000) e Corrêa-Gomes et al. (2005), isto é $N 90^{\circ}-100^{\circ}(17 \%)$ e $N 170^{\circ}-180^{\circ}(11 \%)$, com algumas dispersões menores nos quadrantes NW e SE. Semelhante concentração direcional pode ser notada para os tensores principais mínimos (Fig.6b).

Campos de Tensão na Bacia de Almada De 33 medidas de campos de tensão obtidos na Bacia de Almada, a partir do estudo de 650 planos de falhas e fraturas (Tabela 1 e Fig.7), resultou que: (i) os tensores principais máximos se orientam a N120 $140^{\circ}(24,2 \%)$ e a $N 40^{\circ}-50^{\circ}$ e $N 70^{\circ}-80^{\circ}$ (ambas com $12,1 \%$ ) e (ii) os tensores principais mínimos, de extensão na bacia, se orientam a $\mathrm{N} 40^{\circ}=50^{\circ}(18,2 \%)$, a N $160^{\circ}-170^{\circ}(15,1 \%)$ e a N $120^{\circ}-130^{\circ}(12,1 \%)$.

Três detalhes dessas orientações tensionais chamam a atenção: (i) há duas concentrações de $\sigma$, com caimentos distintos, uma mais vertical dispersa próxima ao centro da rede estereográfica e outra mais horizontal com concentrações próximas à periferia, (ii) tanto $\sigma_{1}$ quantos $\sigma_{3}$ têm concentrações aproximadamente ortogonais entre si e (iii) enquanto $\sigma_{3}$ têm padrões direcionais mais consistentes as de $\sigma_{1}$ são mais dispersas.

DISCUSSÃO Alguns aspectos importantes podem ser apontados no tocante às relações entre as estruturas dúcteis e rúpteis e os campos de tensão da área estudada.

Lineamentos estruturais da Bacia de Almada Várias falhas importantes da Bacia de Almada têm orientação próxima a N-S, coincidente com a foliação regional dos granulitos do Cinturão Itabuna e ao contorno continental da bacia. É também notável o controle estrutural da ZCIIC sobre a bacia incluindo: (i) o mesmo formato centro-convergente dos planos de falhas e fraturas com estrutura em flor, inicialmente positiva, posteriormente retomada em fase extensional para negativa (Corrêa-Gomes 2000) e (ii) as famílias $\mathrm{N}^{\circ} 5^{\circ}, \mathrm{N} 90^{\circ} \mathrm{e} \mathrm{N} 120^{\circ}$ da zona de cisalhamento rúptil. A julgar pela orientação do eixo maior do Canyon do Almada (N120 ), esse controle estrutural deve se estender também para a plataforma continental.

Campos de tensão na Zona de Cisalhamento Itabuna-Itajú do Colônia Os campos de tensão da Zona de Cisalhamento de ItabunaItajú do Colônia podem ser relacionados a uma fase transcompressiva e a uma transextensiva, a primeira com o tensor principal máximo do campo de tensão remoto inicialmente orientado N-S, o qual na segunda fase se orientou E-W (Corrêa-Gomes et al. 2005). Em ambas as fases tectônicas as falhas e fraturas contêm estrias de caimento de baixo ângulo, coincidentes com o observado no perfil realizado a $S W$ da $B A$.

Os campos de tensão na Bacia de Almada Na Bacia de Almada chamam a atenção duas concentrações de caimento de $\sigma_{\bullet}$, uma mais vertical e outra mais horizontal (Fig.8). Das 33 medidas de campos de tensão obtidas na Bacia de Almada 14 se relacionam à tectônica normal $\left(\sigma_{1}\right.$ com alto caimento e estrias dip-slip - Figs.

(a) Tensor máximo principal - $\sigma_{1}$

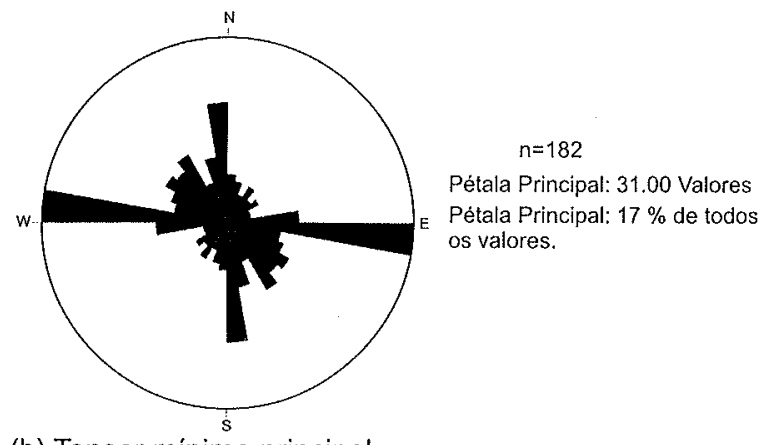

(b) Tensor minimo principal $-\sigma_{3}$

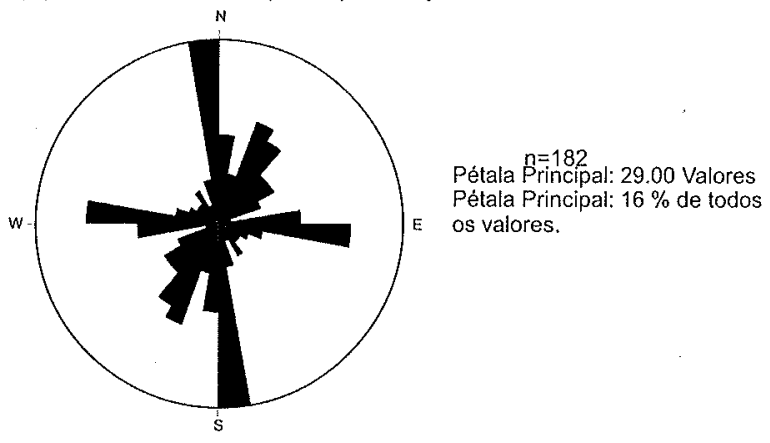

Figura 6 - Plotagem em rosáceas de direção dos campos de

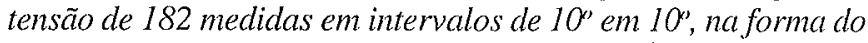
azimute dos tensores principais máximo $(a)$ e mínimo $(b)$, do embasamento distal da Bacia de Almada. 
Tabela 1 - Localização geográfica dos afloramentos onde foram medidos 650 planos rúpteis, e marcadores cinemáticos para obter a orientação dos campos de tensão (33 medidas) associados à falhas de borda e aos pacotes sedimentares da Bacia de Almada.

\begin{tabular}{|c|c|c|c|c|c|c|}
\hline PONTO & COORDENAI & GEOGRÁFICAS & $\begin{array}{c}\text { N" DE PLANOS } \\
\text { DE FALHAS }\end{array}$ & $\sigma_{1}$ & $\sigma_{2}$ & $\sigma_{3}$ \\
\hline \multirow[t]{2}{*}{$\mathrm{P}-012$} & $14^{\circ} 25^{\prime} 08^{\prime \prime}$ & $39^{\circ} 03^{\prime} 27^{\prime \prime}$ & 8 & $\mathrm{~N} 225^{\circ} / 60^{\circ}$ & $\mathrm{N} 315^{\circ} / 00^{\circ}$ & $\mathrm{N} 045^{\circ} / 30^{\circ}$ \\
\hline & & & 18 & N056 $1 / 74^{\circ}$ & $\mathrm{N} 278^{\circ} / 12^{\circ}$ & $\mathrm{N} 186^{\circ} / 10^{\circ}$ \\
\hline \multirow[t]{3}{*}{ P-009 } & $14^{\circ} 2839^{\prime \prime}$ & $39^{\circ} 01^{158^{\prime \prime}}$ & 15 & $\mathrm{~N} 200^{\circ} / 20^{\circ}$ & $N 092^{\circ} / 41^{\circ}$ & $\mathrm{N} 310^{\circ} / 43^{\circ}$ \\
\hline & & & 20 & $\mathrm{~N} 322^{\circ} / 28^{\circ}$ & $\mathrm{N} 112^{\circ} / 58^{\circ}$ & $\mathrm{N} 225^{\circ} / 13^{\circ}$ \\
\hline & & & 15 & $\mathrm{~N} 225^{\circ} / 15^{\circ}$ & $\mathrm{N} 115^{\circ} / 52^{\circ}$ & $\mathrm{N} 325^{\circ} / 34^{\circ}$ \\
\hline P-010 & $14^{\circ} 27^{\prime 3} 39^{\prime \prime}$ & $39^{\circ} 02^{\prime} 22^{\prime \prime}$ & 15 & $N 145^{\circ} / 12^{\circ}$ & $\mathrm{N} 259^{\circ} / 63^{\circ}$ & $\mathrm{N} 049^{\circ} / 24^{\circ}$ \\
\hline ALM-00I & $14^{\circ} 41^{\prime} 52^{\prime \prime}$ & $39^{\circ} 04^{\prime} 36^{\prime \prime}$ & 10 & $\mathrm{~N} 115^{\circ} / 60^{\circ}$ & $\mathrm{N} 205^{\circ} / 00^{\circ}$ & $\mathrm{N} 295^{\circ} / 30^{\circ}$ \\
\hline P-006 & $14^{\circ} 36^{\prime} 28^{\prime \prime}$ & $39^{\circ} 11^{\prime} 44^{\prime \prime}$ & 15 & $\mathrm{~N} 252^{\circ} / 58^{\circ}$ & $\mathrm{N} 072^{\circ} / 31^{\circ}$ & $\mathrm{N} 342^{\circ} / 00^{\circ}$ \\
\hline \multirow[t]{9}{*}{$\mathrm{P}-007$} & $14^{\circ} 39^{\prime} 27^{\prime \prime}$ & $39^{\circ} 11^{\circ} 17^{\prime \prime}$ & 8 & N040"/80" & $\mathrm{N} 130^{\circ} / 00^{\circ}$ & $\mathrm{N} 220^{\circ} / 10^{\circ}$ \\
\hline & & & 3 & N008 $/ 73^{\circ}$ & $\mathrm{N} 207^{\circ} / 16^{\circ}$ & $N 116^{\circ} / 05^{\circ}$ \\
\hline & & & 50 & $N 115^{\circ} / 83^{\circ}$ & $\mathrm{N} 025^{\circ} / 00^{\circ}$ & $\mathrm{N} 295^{\circ} / 07^{\circ}$ \\
\hline & & & 50 & $\mathrm{~N} 130^{\circ} / 76^{\circ}$ & $\mathrm{N} 040^{\circ} / 00^{\circ}$ & $\mathrm{N} 310^{\circ} \% 14^{\circ}$ \\
\hline & & & 5 & $\mathrm{~N} 210^{\circ} / 80^{\circ}$ & $\mathrm{N} 300^{\circ} / 00^{\circ}$ & $\mathrm{N} 030^{\circ} / 10^{\circ}$ \\
\hline & & & 38 & $\mathrm{~N} / 33^{\circ} / 68^{\circ}$ & $\mathrm{N} 250^{\circ} / 10^{\circ}$ & $N 343^{\prime \prime} / 19^{\prime \prime}$ \\
\hline & & & 60 & $\mathrm{~N} 168^{\circ} / 60^{\circ}$ & $\mathrm{N} 074^{\circ} / 02^{\circ}$ & $\mathrm{N} 343^{\circ} / 30^{\circ}$ \\
\hline & & & 10 & $\mathrm{~N} 125^{\circ} / 67^{\circ}$ & $\mathrm{N} 035^{\circ} / 00^{\circ}$ & $\mathrm{N} 305^{\circ} / 23^{\circ}$ \\
\hline & & & 5 & $\mathrm{~N} 125^{\circ} / 53^{\circ}$ & $\mathrm{N} 215^{\circ} / 00^{\circ}$ & $\mathrm{N} 305^{\circ} / 37^{\circ}$ \\
\hline \multirow[t]{2}{*}{ ALM-001 } & $14^{\circ} 41^{\prime} 52^{\prime \prime}$ & $39^{\circ} 04^{\prime} 36^{\prime \prime}$ & 8 & $N 062 \% 16^{\circ}$ & $\mathrm{N} 244^{\circ} / 74^{\circ}$ & N152\% $101^{\circ}$ \\
\hline & & & 7 & $\mathrm{~N} 350^{\circ} / 03^{\circ}$ & $\mathrm{N} 104^{\circ} / 82^{\circ}$ & $\mathrm{N} 260 \% 07^{\circ}$ \\
\hline \multirow[t]{2}{*}{ ALM-002 } & 14'39'33" & $39^{\circ} 05^{\prime} 52^{\prime \prime}$ & 20 & N094\% $/ 02^{\circ}$ & $\mathrm{N} 356^{\circ} / 75^{\circ}$ & $N 189^{\circ} / 15^{\circ}$ \\
\hline & & & 5 & $\mathrm{~N} 134 \% 10^{\circ}$ & $\mathrm{N} 000^{\circ} / 76^{\circ}$ & $\mathrm{N} 226^{11} / 10^{\circ}$ \\
\hline P-005 & $14^{\circ} 36^{\prime} 31^{\prime \prime}$ & $39^{\circ} 11^{\prime} 46^{\prime \prime}$ & 45 & $\mathrm{~N} 076^{\circ} / 00^{\circ}$ & VERTICAL & $\mathrm{N} 346 \% 00^{\circ}$ \\
\hline \multirow[t]{2}{*}{ P-006 } & $14^{\circ} 36^{\prime} 28^{\prime \prime}$ & $39^{\circ} 11^{\prime} 44^{\prime \prime}$ & 25 & $\mathrm{~N} 300^{\circ} / 06^{\circ}$ & $\mathrm{N} 165^{\circ} / 81^{\circ}$ & N030\% $106^{\circ}$ \\
\hline & & & 20 & $\mathrm{~N} 076^{\circ} / 00^{\circ}$ & $N 166^{\circ} / 79^{\circ}$ & $\mathrm{N} 346^{\circ} / 11^{\circ}$ \\
\hline \multirow[t]{4}{*}{ P.007 } & $14^{\circ} 39^{\prime} 27^{\prime \prime}$ & $39^{\circ} 11^{\prime} 17^{\prime \prime}$ & 30 & $\mathrm{~N} 142^{\circ} / 24^{\circ}$ & $\mathrm{N} 324^{\prime \prime} / 66^{\prime \prime}$ & $\mathrm{N} 232^{\circ} / 01^{\circ}$ \\
\hline & & & 10 & $\mathrm{~N} 305^{\circ} / 23^{\circ}$ & $\mathrm{N} 215^{\circ /} / 00^{\prime \prime}$ & $\mathrm{N} 125^{\circ} / 67^{\circ}$ \\
\hline & & & 5 & $\mathrm{~N} 106^{\circ} / 08^{\prime \prime}$ & $\mathrm{N} 240^{\prime \prime} / 78^{\circ}$ & No14\% $/ 08^{\circ}$ \\
\hline & & & 60 & $\mathrm{~N} 211^{\circ} / 13^{\prime \prime}$ & $N 001^{\circ} / 74^{\circ}$ & $\mathrm{N} 120^{\circ} / 08^{\circ}$ \\
\hline ZCl-001 & $14^{\circ} 40^{\prime} 53^{\prime \prime}$ & $39^{\circ} 04^{\prime} 39^{\prime \prime}$ & 10 & $\mathrm{~N} 059^{\circ} / 10^{\circ}$ & $\mathrm{N} 285^{\circ} / 75^{\circ}$ & $N 151^{\circ} / 10^{\circ}$ \\
\hline
\end{tabular}

(a) Tensores máximos $\left(\sigma_{1}\right)$
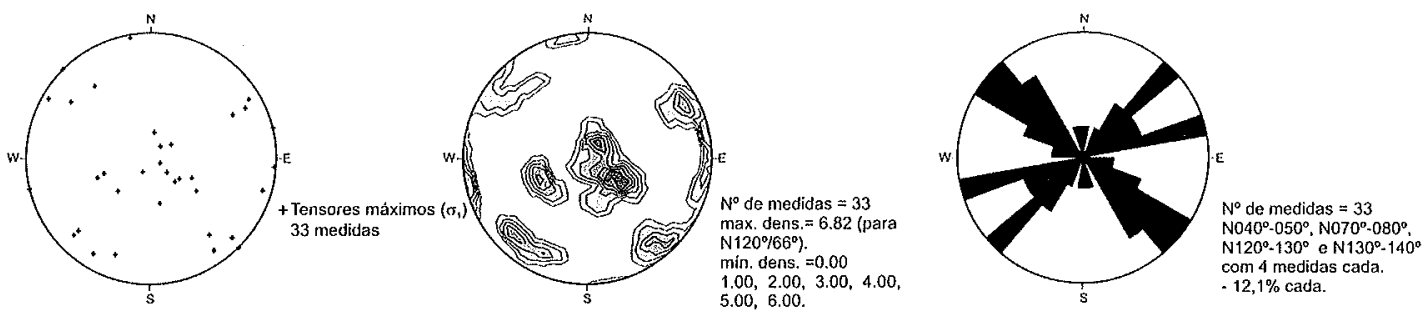

(b) Tensores mínimos $\left(\sigma_{3}\right)$
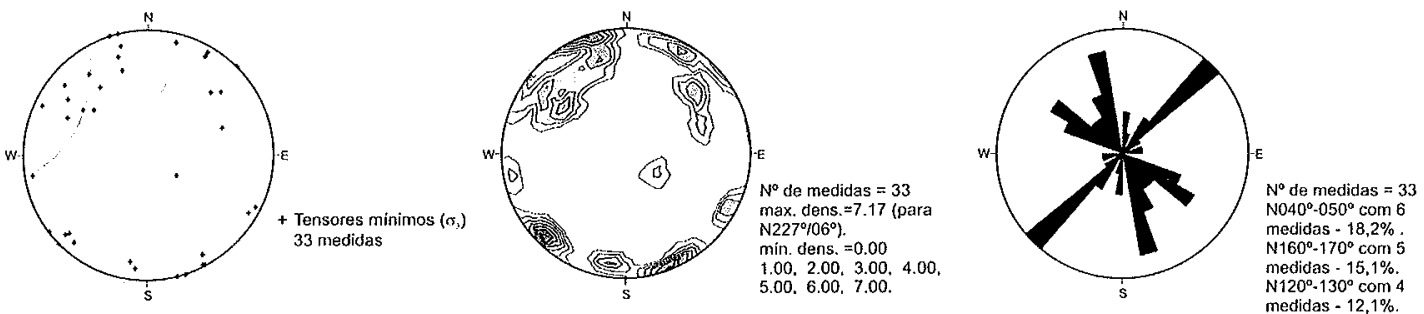

Figura 7 - Campos de tensão da Bacia de Almada - como pólos e em campos de isodensidade em rede estereográfica igual-área, hemisfério inferior, e em rosáceas de direções, intervalos de 10"dos tensores principais máximo (a) e mínimo (b) obtidos na Bacia de Almada - total de 33 medidas. Notar em (a) a existência de duas concentrações de $\sigma_{1}$, uma mais próxima ao centro e outra mais próxima à periferia da rede estereográfica. 
(a)

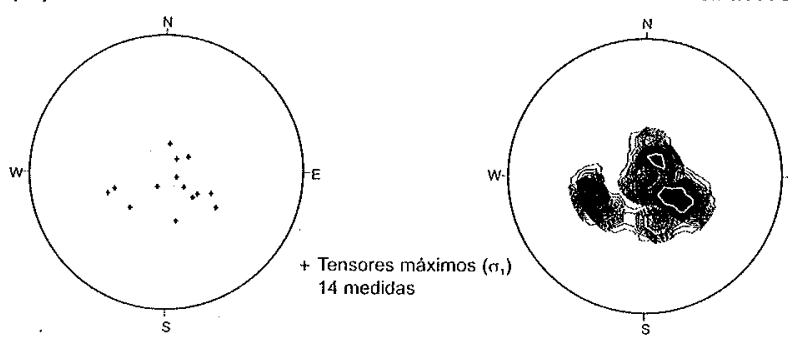

Tensores máximos normais $\left(\sigma_{1}\right)$

Tensores mínimos normais $\left(\sigma_{3}\right)$
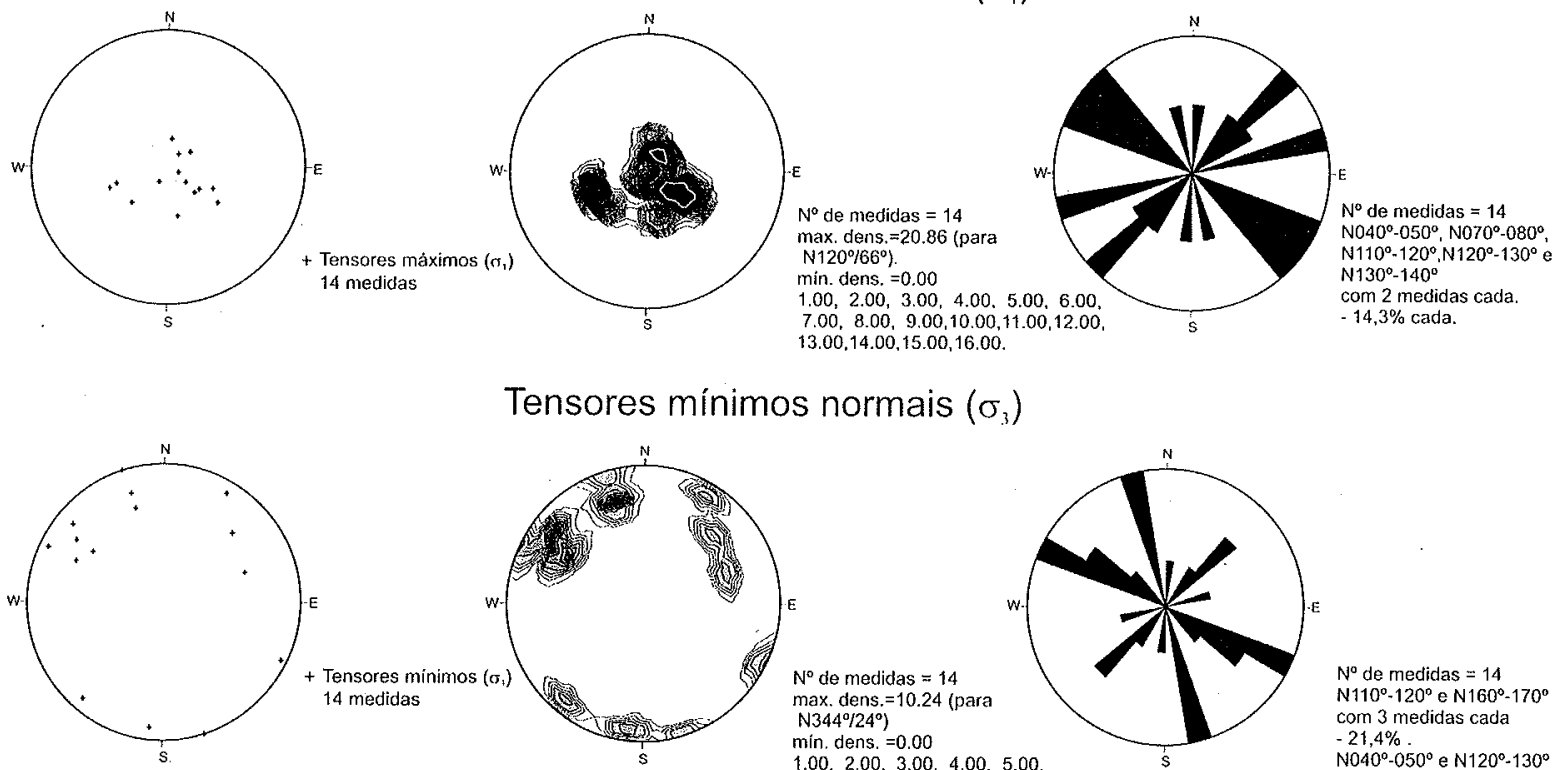

$7.00,8.00,9.00,10.00,11.00,12.00$ $13.00,14.00,15.00,16.00$

(b)

Tensores máximos transcorrentes $\left(\sigma_{1}\right)$
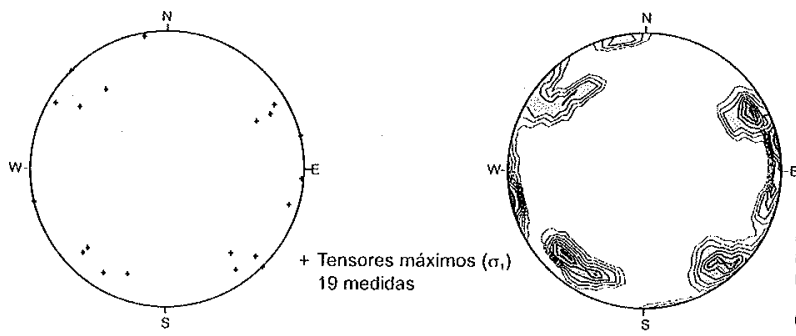

$N^{\circ}$ de medidas $=14$ max. dens. $=10.24$ min. dens. $=0.00$

$100,200,3.00,4.00,5.00$ $1.00,2.00,3.00,4.00,5.00$

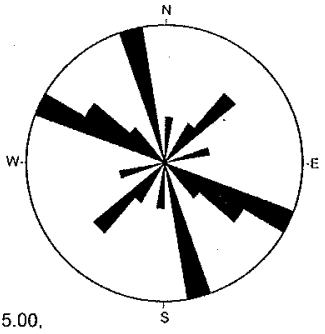

No de medidas $=14$ com 3 medidas $\mathrm{Cod}^{\circ}-170^{\circ}$ $-21,4 \%$ NO $40^{\circ}-050^{\circ}$ e N $120^{\circ}-130^{\circ}$ com 2 medidas cada
$-14,3 \%$.

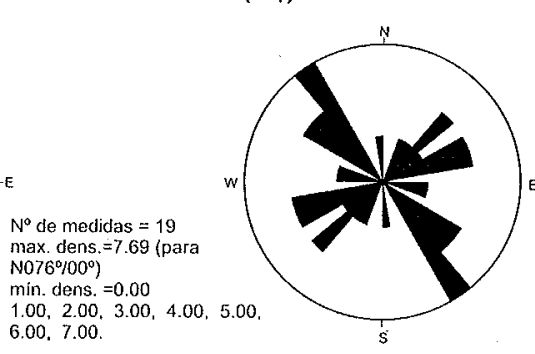

$N^{\circ}$ de medidas $=19$ $\mathrm{N} 140^{\circ}-150^{\circ} \mathrm{com} 3$ modidas - $15,8 \%$. $\mathrm{N} 070^{\circ}-080^{\circ}, \mathrm{N} 120^{\circ}-130^{\circ}$ $\mathrm{N} 130^{\circ} \sim 140^{\circ}$ com 2 medidas cada.

Tensores mínimos transcorrentes $\left(\sigma_{3}\right)$
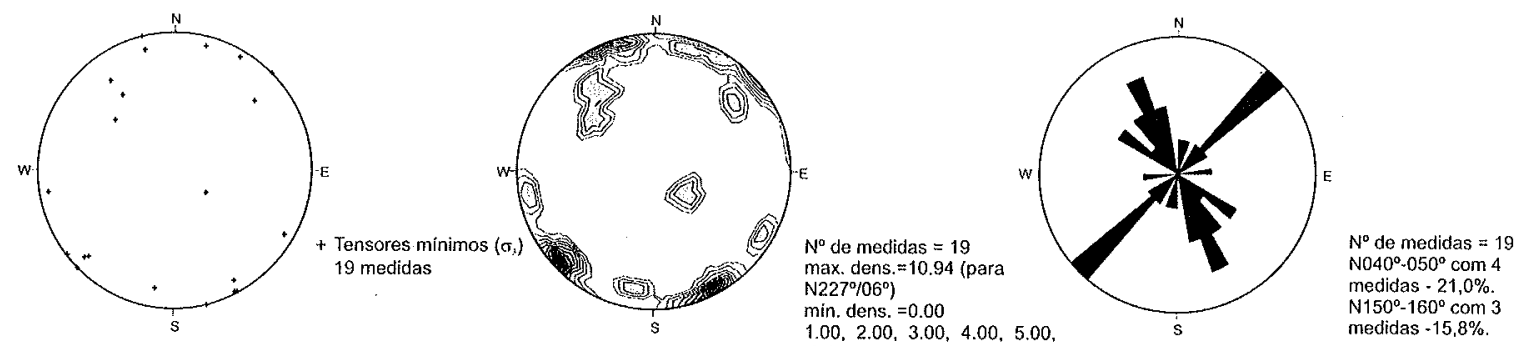

Figura 8 - Campos de tensão das falhas normais (a) e transcorrentes (b) - como pólos e em campos de isodensidade em rede estereográfica igual-área, hemisfério inferior, e em rosáceas de direções, intervalos de $10^{\prime \prime}$ - dos tensores principais máximo e mínimo obtidos na Bacia de Almada - total de 33 medidas.

$9 \mathrm{a}, \mathrm{b}, \mathrm{c}, \mathrm{d})$ e 19 à transcorrente $(\sigma$, com baixo caimento e estrias strike-slip - Figs. 9e,f). A análise separada desses sub-domínios revelou que: (i) nos casos das falhas gravitacionais há ampla distribuição de orientações do tensor principal máximo, o que necessitou analisar as orientações dos tensores principais mínimos revelando 4 direções de extensão, isto é N1 $10^{\circ}-120^{\circ}$ e N160 $170^{\circ}$ (3 medidas cada) e $N 40^{\circ}-50^{\circ}$ e N $120^{\circ}-130^{\circ}$ ( 2 medidas cada) e (ii) nas transcorrentes houve melhor distribuição de concentrações direcionais, tanto de $\sigma_{1}$, notadamente próximas de $N 130^{\circ}$ a $150^{\circ} \mathrm{e}$ $\mathrm{N} 40^{\circ}$ a $N 80^{\circ}$, quanto de $\sigma_{3}$, com concentrações importantes a $\mathrm{N} 40^{\circ}$ -

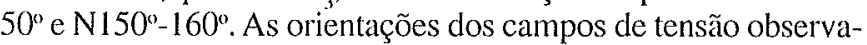

das na ZCIIC são, portanto, diferentes daquelas observadas na área da Bacia de Almada onde, inicialmente, dominaram padrões de falhas gravitacionais em planos sub-verticais com estrias dipslip, menos freqüentes na ZCIIC, e orientações de $\sigma_{1}$ e $\sigma_{3}$ dispersas ao redor da bacia. Nos planos de falhas normais as estrias subverticais são parcialmente obliteradas por estrias strike-slip (Figs.9c,d), relacionadas a falhas transextensivas, cujos $\sigma_{\text {d deno- }}$ tam orientações mais consistentes e distintas das obtidas na ZCIIC.

Padrões de falhamento e a evolução tectônica da Bacia deAImada Usualmente o estudo de geração de falhas e fraturas múltiplas 

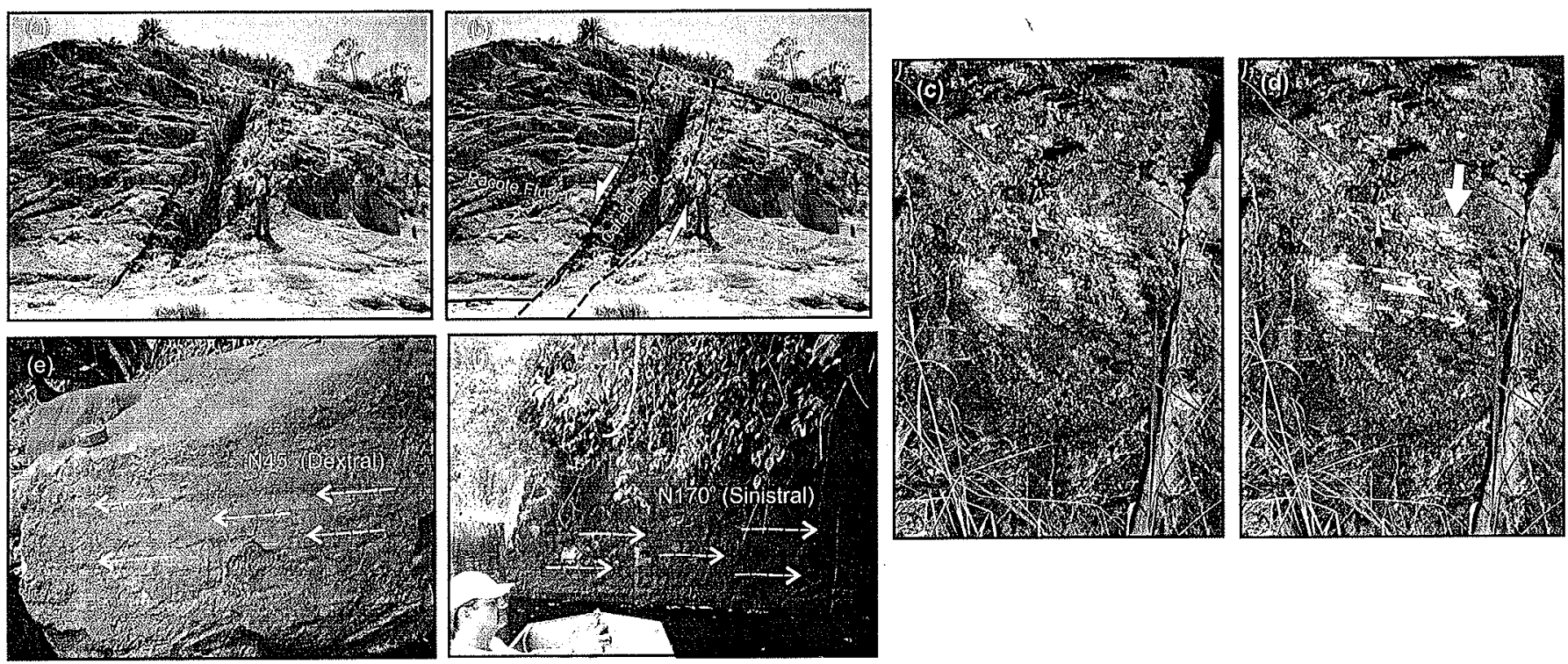

Figura 9 - Fotografias de falhas da Bacia de Almada. (a) falha normal-dextral N45"/78'SE com estrias dip-slip, que afeta pacotes eólico e fluvial da Formação Sergi, em (b) interpretação geológica; (c) plano de falha de borda $N$-S, com degraus de cinemática normal (seta branca) parcialmente polidos por estrias produzidas de cinemática sinistral (semi-seta branca) e (e) e $(f)$ estrias sub-

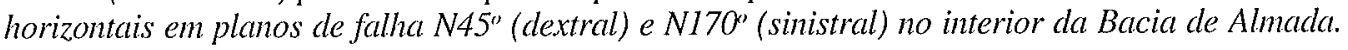

(a)

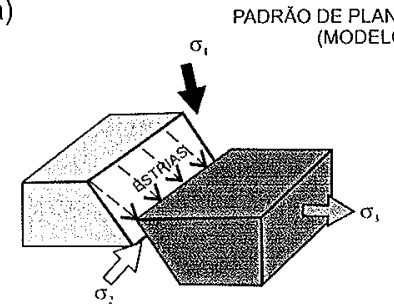

(c)

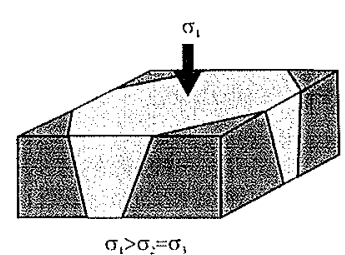

(b)

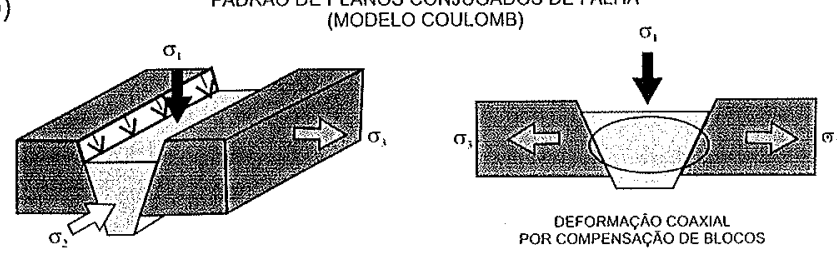

(d)

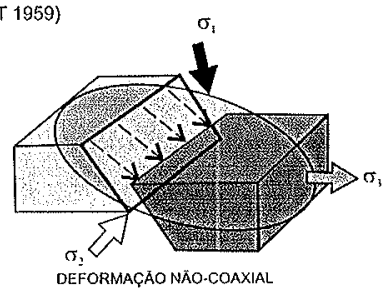

PADRÃO COMPLEXO DE PLANOS MÚLTIPLOS OE FALHA (MODELO NIETO-SAMANIEGO \& ALANIZ-ALVAREZ 1997)
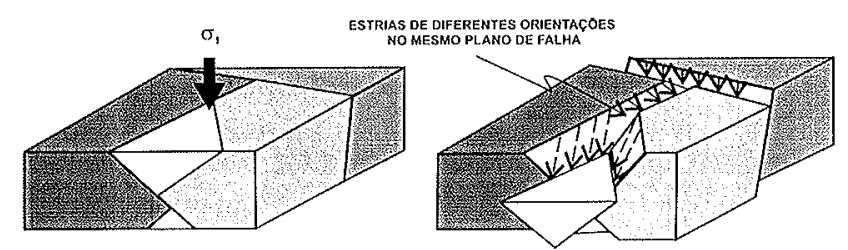

Figura 10 - Os quatro principais padrões de falhamento, notar que em todos existe um componente normal de movimentaçäo dos blocos (Nieto-Samaniego 1999): (a) falhas isoladas segundo o modelo de Bott (1959), (b) falhas conjugadas do tipo Coulomb, (c) falhas ortorrômbico-romboédrica tridimensional segundo modelo de Reches (1978) e (d) complexo de falhas múltiplas segundo modelo de blocos interativos de Nieto-Samaniego \& Alaniz-Alvarez (1997). Em cada caso há diferentes relações entre orientação espacial das estrias produzidas, movimentação de blocos e as interseções dos planos de falhas, deformação coaxial (não-rotacional) e deformação não-coaxial (rotacional), magnitudes de $\sigma_{1}, \sigma_{2}$ e $\sigma_{3}$, e geração de mais de um jogo de estrias no mesmo plano de falha.

considera padrões dos tipos (Nieto-Samaniego 1999) (Fig.10):

(i) falhas isoladas (Fig. 10a), por produção de falhas ou reativação de falhas pré-existentes, conforme o modelo de Bott (1959), sendo geradas por deformações rotacionais bidimensionais ou tridimensionais e geração de slickenlines convergentes para as interseções das falhas, isto é no sentido do $\sigma_{2}$, e

(ii) Coulomb ou conjugado (Fig. 10b), no qual dois sets conjugados de falhas são produzidos por deformação não-rotacional bidimensional, um dos planos de falha compensando o outro lateralmente, com geração de estrias convergentes para a intercessão das falhas e também no sentido do $\sigma_{2}$.

No entanto, padrões mais complexos podem ocorrer; como os dos tipos:

(iii) ortorrômbico-romboédrico (Fig. 10c), no qual se formam quatro sets de falhas com simetria ortorrômbico-romboédrica, produzidos por deformação tridimensional (triaxial) não-rotacional, 

Almada, Bahia
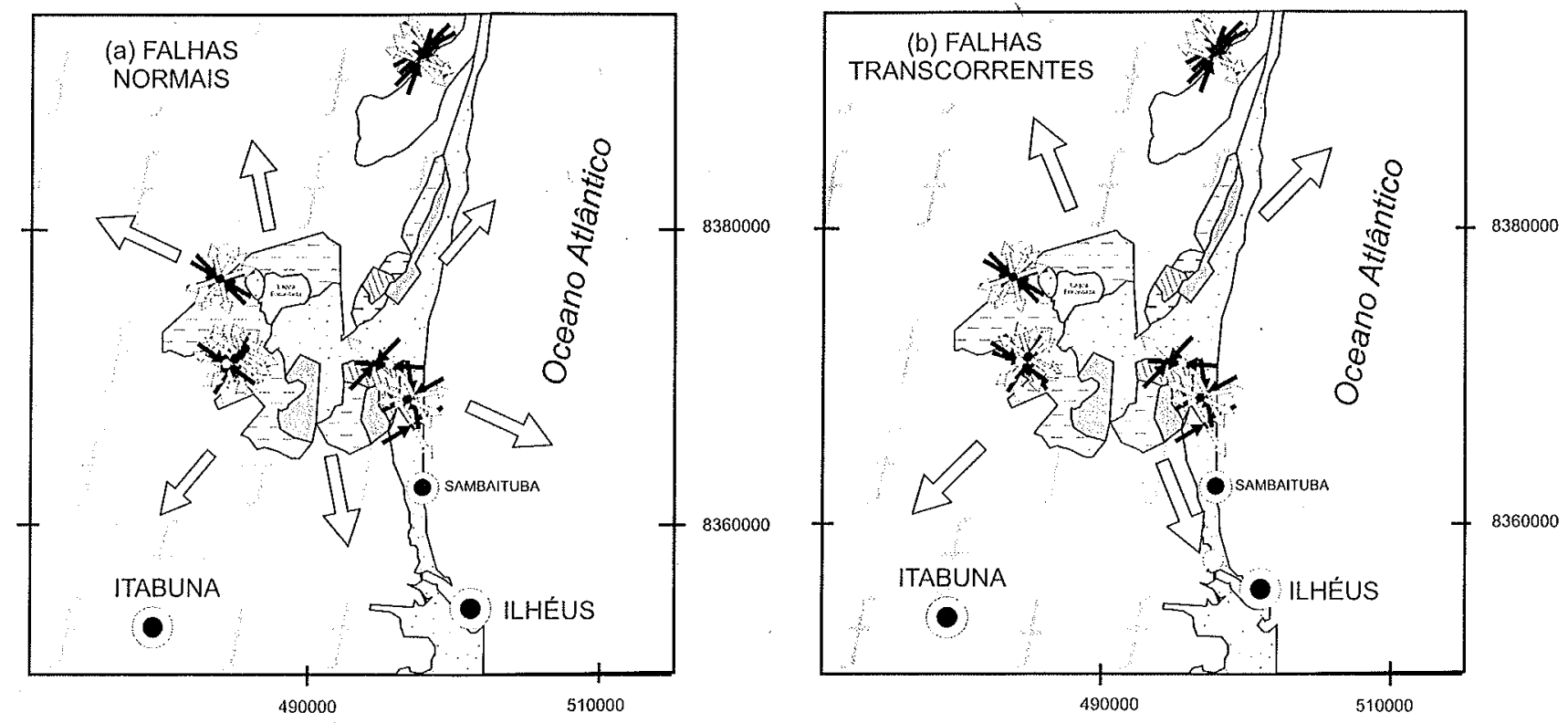

Figura 11 - Orientação dos tensores principais mínimos (sentidos de extensão = setas brancas maiores) da primeira fase tectônica de falhas normais (a) e da segunda de falhas transcorrentes (b) na Bacia de Almada. Legenda como na Figura 4.

segundo o modelo de deslizamento de Reches (1978), com estrias paralelas às intercessões das falhas, e

(iv) complexo (Fig. 10d), sem restrições quanto ao número de sets e à simetria, no qual são produzidas falhas por deformação biou tridimensional, rotacional ou não-rotacional, com slickenlines paralelas às interseções das falhas e, em um mesmo plano, podendo ter orientações totalmente diferentes, conforme o modelo de interação de blocos de Nieto-Samaniego \& Alaniz-Alvarez (1997).

Os padrões mais complexos, ortorrômbico-romboédricos e múltiplos complexos, podem ser produzidos desde em bacias sedimentares tipo rift-valley até em ensaios em blocos de argila (Reches 1978).

Assim, conjugando os modos de falhamento, a orientação espacial de planos de falhas-fraturas e os campos de tensão na Bacia de Almada, algumas observações importantes podem ser feitas: (i) praticamente todos os lineamentos estruturais que mo-

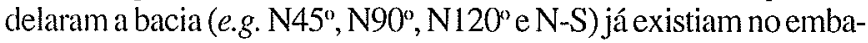
samento da mesma e foram reativados, (ii) na primeira fase, $\operatorname{com} \sigma_{1}$ de alto caimento, dominou a tectônica responsável pela geração de falhas normais, com estrias paralelas a interseção das mesmas e com orientação dos tensores principais mínimos indicativa de deformação ortorrômbico-romboédrica 3D, com abertura simultânea de blocos em direções ortogonais a sub-ortogonais às principais falhas de contorno da bacia (Fig. I la), e (iii) na segunda fase, com $\sigma$ de baixo caimento, dominou a tectônica transextensiva e as orientações dos campos de tensão foram consistentès, com duas orientações extensionais $\mathrm{N}^{\circ}$ e $\mathrm{N} 150^{\circ}$, o que indica pulsos (ou sub-eventos) de extensão com alternância de orientações quase ortogonais em dentro da bacia (Fig. 11 b).

CONCLUSÕES Do estudo das estruturas da Bacia de Almada e do seu embasamento cristalino se conclui que: (i) a mesma foi fortemente controlada por estruturas dúcteis e rúpteis herdadas do orógeno paleoproterozóico Itabuna e pela Zona de cisalhamento neoproterozóica de Itabuna-Itajú do Colônia, que compõem seu embasamento, e por falhas paralelas ao atual contorno continental, relacionadas à separação continental mesozóica, (ii) a orientação dos campos de tensão do embasamento e na bacia são distintos e foram formados em épocas diferentes, (iii) o padrão de orientação dos campos de tensão na bacia indica que a mesma foi polifásica, inicialmente produzida por falhas normais em padrão ortorrômbico-romboédrico triaxial e evoluiu para regime transextensivo em pulsos (ou sub-fases tectônicas), com mudanças de orientação do tensor principal máximo quase ortogonais entre si. Isto abre novas perspectivas e subsidia a prospecção de hidrocarbonetos e água subterrânea na região continental e de hidrocarbonetos na região offshore da Bacia de Almada.

Agradecimentos Ao $\mathrm{CNPq}$ pelo suporte financeiro (processo $\mathrm{n}$ 478248/2001-6) ao projeto "Neotectônica litorânea do SSE do estado da Bahia" coordenado por LCCG e às bolsas de produtividade de LCCG, JSFB e JMLD; ao Prof. Dr. João Batista G. Teixeira do IGEO-UFBA, e aos geólogos da CPRM-BA e CBPM pelas informações prestadas e discussões realizadas durante as fases de campo. Aos revisores da RBG pelas valiosas sugestões ao manuscrito.

\section{Referências}

Allmendinger R. 2001. www. geo.cornell.edu/pub/rwa/windows.

Arcanjo J.B.A. 1993. Folha de Itabuna SD.24.Y.B.VI, Estado da Bahia, escala 1:100.000. DNPM/CPRM, Brasília, inédito.

Barbosa J.F.S. \& Dominguez J.M.L. (eds.) 1996. Mapa Geológico do
Estado da Bahia. Texto Explicativo. Secretaria da Indústria Comércio e Mineração, Superintendência de Geologia e Recursos Minerais, Salvador, Bahia, 400p.

Barbosa J.S.F. \& Corrêa-Gomes L.C. (eds.) 2003. I Workshop sobre o Orógeno Itabuna-Salvador-Curaça - I WOISC. Geologia e guias de 
excursão de campo. Revi. Bras. Geoc., 33(1-Suplemento):1-88.

Barbosa J.S.F. \& Sabaté P. 2004. Archean and Paleoproterozoic crust of the São Francisco Cráton, Bahia, Brazil: geodynamic features. Prec. Res., 133:1-27.

Barbosa de Deus P., Rangel P.A., Silveira W.P., Viana I.A., Alecrim J.D., Villas Boas A., Pamponet L.T.C., Araújo J.B., Rodrigues J.B., Cardoso P.C.S., Vasconcellos H.G., Garrido I.A.A., Ribeiro W., Bezerra A.T., Rego J.E., Silva N.S., Siqueira L.P., Bezerra J.C.L., Souto P.G. 1976. Projeto Rochas Alcalinas de Itarantim- Fase I. Texto e fichas petrográficas. SME/CPM, Convênio SME/CBPM. Estado da Bahia, Salvador, $160 \mathrm{p}$.

Bott M. H. P. 1959. The mechanics of oblique slip faulting. Geol. Mag., 96:109-117.

Bruhn C.H.L. \& Moraes M.A.S. 1989. Turbiditos da Formação Urucutuca na Bacia de Almada, Bahia: um laboratório de campo para estudo de reservatórios canalizados. Boletin de Geociências da PETROBRAS, Rio de Janeiro, 3:235-267.

Carvalho K.W.B. 1965. Geologia da Bacia Sedimentar do Rio Almada. Boletim Técnico da PETROBRAS, 8:5-55.

Conceição H. \& Otero O.M.F. 1996. Magmatismo granítico e alcalino no estado da Bahia. Um epítome do tema. Convênio SICM/SGM/ PPPG/UFBA, 133 p.

Corrêa-Gomes L.C. 2000. Evolução dinâmica da Zona de Cisalhamento Neoproterozóica de Itabuna-Itají do Colônia e do magmatismo fissural alcalino associado (SSE do Estado da Bahia, Brasil). Tese de Doutoramento, IG/UNICAMP, 239p.

Corrêa-Gomes L. C. \& Oliveira E. P. de 2002. Geocronologia Pb-Pb, Sm$\mathrm{Nd}$ e $\mathrm{Ar} / \mathrm{Ar}$ de corpos plutônicos das zonas de cisalhamento neoproterozóicas de Potiraguá e Itabuna-Itajú do Colônia, SSE Bahia, Brasil: contribuição ao entendimento da evolução tectônica no limite Orógeno Araçuaí/Cráton do São Francisco. Rev. Bras. Geoc., 32:85196.

Corrêa-Gomes L.C., Oliveira E.P., Barbosa J.S.F., Silva P.C.F. 1998. Tectônica associada à colocação de diques alcalinos félsicos e máficos neoproterozóicos na Zona de Cisalhamento de Itabuna-Itajú do Colônia, Bahia, Brasil. Rev. Bras. Geoc., 28:497-508.

Corrêa-Gomes L.C., Souza Filho C.R., Oliveira E.P. 2000. Paleostress fields and 3-D structure of polyphasic shear zones in the transition Craton-Orogenic Belt: Examples from the Neoproterozoic of Southeastern Bahia, Brazil. Volume "Brazilian contributions to $31^{\text {sl }}$ International Geological Congress, Brazil 2000", Rev. Bras. Geoc, 30:153-156.

Corrêa-Gomes L.C., Oliveira E.P. de, Souza Filho C.R. de. 2005. Evolução tectônica no Neoproterozóico da interface Cráton do São Francisco/Orógeno Araçuại, no SSE do Estado da Bahia, Brasil. In: M.L.S. Rosa , M. Kosin, D.C. Rios, M. Santos-Pinto, J.B.G.Teixeira, (eds.), III Simpósio sobre o Cráton do São Francisco, Salvador, Bahia, Anais, pp. $211-214$.
D'Ávila R.F., Souza Cruz C.E., Ferreira E.A. 2002. Reinterpretação do Canyon de Almada. In: Simp. Sedimentologia e Estratigrafia: Aplicação dos Estudos de Rocha nas Áreas de Exploração e Desenvolvimento da Produção, 1, Vitória. PETROBRAS, Rio de Janeiro, Resumos, Rh. Uc.

D'Ávila R.S.F., Souza Cruz C.E., Oliveira Filho J.S., Jesus C.M., Cesero P., Dias Filho D.C., Lima C.C., Queiroz C.L., Santos S.F., Ferreira E.A. 2004. Fácies e Modelo Deposicional do Canyon de Almada, BA. In: C. A. Dias (ed.). Turbiditos da Bacia de Almada/Bahia: Pesquisas Geológicas e Geofísicas, Macaé, UENF, pp.: 41-69.

Karam M. R. K. 2005. Integração de ferramentas multidisciplinares para o estudo de feições tectônicas e sismoestratigráficas na sequiência pós-rifte da Bacia de Camamu-Almada, Bahia. Tese de doutoramento, IC/UFRJ, 204p.

Lima M .I. C. de, Fonseca E. G. da, Oliveira, E. P. de, Ghignome J.I., Rocha R. M., Carmo U. F., Silva J. M. R., Siga Jr. O. 1981. Folha SD24. Salvador: Cap. 1 - Geologia. Projeto RADAMBRASIL, Brasil, Ministério das Minas e Energia. Secretaria Geral, 24:27-192.

Martins A. A. M. \& Santos R. A. dos. S. 1993. Folha de lbicaral. SD.24.Y.B.V, Estato da Bahia, escala 1:100.000. DNPM/CPRM, Brasília, inédito.

Mascarenhas J. F. 1979. Evolução geotectônica do pré-cambriano no estado da Bahia. In: H.A.V. Inda (ed.) Geologia e Recursos Minerais do estado da Bahia, textos básicos, SME/CPRM, 2:57-165.

Nieto-Samaniego A. F. 1999. Stress, strain and fault patterns. J. Struct. Geol., 21:1065-1070.

Nieto-Samaniego A. F. \& Alaniz-Alvarez S.A. 1997. Origin and tectonic interpretation of multiple fault patterns. Tectonophysics, 270:197206.

Pedrosa Soares A. C., Noce C. M., Vidal, Ph., Monteiro R. B. P. 1992. Toward a new tectonic model for the Late Proterozoic Araçuaí: (SE Brazil)- West Congolian (SW Africa) Belt. Journal of South America Earth Science, 6:33-47.

Pedrosa Soares A. C., Noce C. M., Wiedimann C. N. M. Pinto C.P. 2001. The Araçuaí West-Congo Orogen in Brazil: an overview of a confined orogen formed during Gondwanaland assembly. Prec. Res., 110:307323.

Reches Z. 1978. Analysis of faulting in three-dimensional strain field. Tectonophysics, 19:109-129.

Silva Filho M.A., Mascarenhas J.F., Moraes Filho O., Gil C.A.A., Santos R.A., Silva L.C., Sampaio A.R., Silva Filho G.R., Pedreira A.J., Ferreira A.V.F., Bruni D.C. 1974. Projeto Sul da Bahia. Relatório Final. Convênio DNPM/CPRM, Salvador, CPRM, 15 vols.

Manuscrito A-1639

Recebido em 28 de utubro de 2005

Revisão dos autores em 20 de novembro de 2005 Revisão aceita em 20 de dezembro de 2005 